\title{
Atık Kevların Beton Yol Kaplamalarında Kullanılabilirliğinin Araştırılması
}

\author{
Mustafa Uraz Tunçel ${ }^{1}$ Osman Ünsal Bayrak ${ }^{2 *}$, Fatih İrfan Baş ${ }^{3}$, Halim Ferit Bayata ${ }^{4}$ \\ ${ }^{1}$ Türk Telekom Erzurum Bölge Müdürlüğü, Erzurum, Türkiye (ORCID: 0000-0003-3030-9108) \\ ${ }^{2}$ Atatürk Üniversitesi, Mühendislik Fakültesi, İnşaat Mühendisliği Bölümü, Erzurum, Türkiye (ORCID: 0000-0003-4039-1248) \\ ${ }^{3}$ Erzincan Binali Yıldırım Üniversitesi, Mühendislik Fakültesi, İnşaat Mühendisliği Bölümü, Erzincan, Türkiye (ORCID: 0000-0002-0845-060X) \\ ${ }^{4}$ Erzincan Binali Yıldırım Üniversitesi, Mühendislik Fakültesi, İnşaat Mühendisliği Bölümü, Erzincan, Türkiye (ORCID: 0000-0001-8274-8888)
}

(İlk Geliş Tarihi 29 Ocak 2020 ve Kabul Tarihi 6 Temmuz 2020)

(DOI: 10.31590 /ejosat.678672)

\begin{abstract}
ATIF/REFERENCE: Tunçel, M. U., Bayrak, O. Ü., Baş, F. İ. \& Bayata, H. F. (2020). Atık Kevların Beton Yol Kaplamalarında Kullanılabilirliğinin Araştırılması. Avrupa Bilim ve Teknoloji Dergisi, (19), 668-678.

$\ddot{O} \mathbf{z}$

Günümüzde haberleşme sektöründe genel olarak fiber optik kablolar kullanılmaktadır. Ülkemizde sadece Türk Telekom operatöründe 256 bin km diğer operatörlerde ise 68 bin km olmak üzere yaklaşık olarak 324 bin km fiber kablo bulunmaktadır. 20 yıl dayanım ömrü olan bu kabloların zamanla yenilenmesi gerekmekte ve kullanım dışı kalan kablolar ise hurdaya ayrılmaktadır. Yıllık olarak ortalama 15 bin km kablo hurdaya ayrılmaktadır. $1 \mathrm{~km}$ kabloda yaklaşık $5 \mathrm{Kg}$ kevlar atık hale gelmektedir. Atık kevların ayrı bir kullanım alanı olmadığından ekonomiye tekrar kazandırılamamaktadır. Bu çalışmada, kevlar ile üretilen betonların yol üstyapısında kullanılabilirliği araştırılmıştır. Bu amaçla, su/bağlayıcı oranı $(0.40,0.45,0.50)$, silis dumanı $(\% 0,5,10$ çimento yerine $)$, kevlar $(0$ gr/m3, 500 gr/m3, $1000 \mathrm{gr} / \mathrm{m} 3)$ ve polipropilen lif (0 gr/m3, $500 \mathrm{gr} / \mathrm{m} 3,1000 \mathrm{gr} / \mathrm{m} 3)$ karışım değişkenleri olarak belirlenmiştir. Tam faktöriyel deney tasarımına göre basınç mukavemeti, kopma modülü ve elastisite modülü deneylerinin herbiri için 3 x $34=243$ tane numunenin dökülmesi gerekmektedir. Genel toplam alındığında tam faktöriyel deney tasarımı uygulanması halinde 729 tane numune gerekmektedir. Bu nedenle, deney tasarımı için Taguchi metodu kullanılmış ve elastisite modülü ile 28 günlük eğilme ve basınç mukavemetini veren optimum karışım değişkenleri belirlenmiştir. Faktör ve seviye sayısı göz önüne alınarak L9 ortogonal dizi, deney tasarımı olarak seçilmiştir ve toplam 3x9x3=81 numune ile 729 numune ile yapılacak çalışma temsil edilmiştir. Deney sonuçlarından, Kevlar malzemesinin betonun basınç, eğilme ve elastisite modülü değerlerine, beton içerisinde $500 \mathrm{~g} / \mathrm{m} 3 \mathrm{kadar}$ katılması durumunda olumlu etkilerde bulunduğu gözlemlenmiştir. Deneylerde polipropilen lif ve kevlar beraber denenmiş olduğundan sadece kevlar kullanımında bu oranın artacağı öngörülmektedir. Elde edilen sonuçlardan, atık malzeme olan kevların, betona katılması ile ekonomiye kazandırılabileceği görülmüştür.
\end{abstract}

\section{Investigation of the Usability of Waste Kevlars in Concrete Road Pavements}

\begin{abstract}
At the present time, fiber optic cables are generally used in the communication sector. In our country, there are 324 thousand km of fiber cables including only 256 thousand $\mathrm{km}$ in Turk Telekom operators and 68 thousand $\mathrm{km}$ in other operators. These cables, which have a service life of 20 years, need to be renewed over time and the cables that are out of use are scrapped. An average of $15,000 \mathrm{~km}$ of cable is scrapped annually. Approximately $5 \mathrm{Kg}$ of kevlars become waste in $1 \mathrm{~km}$ length cable. Since waste kevlars do not have a separate usage area, they cannot be recycled to the economy. In this study, the usability of the concrete produced with kevlar on the road
\end{abstract}

\footnotetext{
* Sorumlu Yazar: Atatürk Üniversitesi, Mühendislik Fakültesi, İnşaat Mühendisliği Bölümü, Erzurum, Türkiye, ORCID: 0000-0003-4039-1248, unsalb@atauni.edu.tr
} 
superstructure was investigated. For this purpose, water / binder ratio $(0.40,0.45,0.50)$, silica fume $(\% 0,5,10$ instead of cement), kevlar $(0 \mathrm{gr} / \mathrm{m} 3,500 \mathrm{gr} / \mathrm{m} 3,1000 \mathrm{gr} / \mathrm{m} 3)$ and polypropylene fiber $(0 \mathrm{gr} / \mathrm{m} 3,500 \mathrm{gr} / \mathrm{m} 3,1000 \mathrm{gr} / \mathrm{m} 3)$ are determined as mixture variables. According to the full factorial experiment design, 3 x $34=243$ samples must be poured for each of the compressive strength, rupture modulus and elasticity modulus tests. In the case of a grand total, 729 samples are required if a full factorial experiment design is applied. For this reason, Taguchi method was used for the experimental design and optimum mixture variables that gave 28 days of flexural and compressive strength were determined by the modulus of elasticity. Considering the factor and number of the levels, the L9 orthogonal array was chosen as the experimental design and the study to be performed with a total of 3x9x3=81 samples and 729 samples was represented. From the results of the experiment, it has been observed that Kevlar material has positive effects on the compressive, flexural and elasticity modulus values added up to $500 \mathrm{~g} / \mathrm{m} 3$ in the concrete. Since polypropylene fiber and kevlar were tested together in the experiments, it is predicted that this rate will increase only in the use of kevlar. From the results, it was observed that Kevlar which is a waste material can be brought to the economy by adding to the concrete.

Keywords: Kevlar, Rigid Pavement, Polypropylene Fiber, Taguchi Method

\section{Giriş}

Karayollarında uygulanan üstyapılar çevre koşullarına göre dayanıklı, üzerine gelen yükleri zemine ileten mühendislik yapılarıdır. Kaplama tabakasında bağlayıcı olarak bitüm kullanılan üst yapılara esnek üstyapı, çimento kullanılan üst yapılara ise rijit üstyapılar denilmektedir. Beton kaplama uygulamaları, ağır trafiğe ve çok yüksek trafik hacmine sahip karayollarında ve havaalanları uygulamalarında sürüş emniyeti ve sürüş konforu sağlamak amacı ile yapılan yüksek standartlı rijit üstyapılardır. Beton kaplamalar, yeter mukavemete sahip zeminler üzerine belirli bir kalınlıkta serilen granüler alttemel tabakası ile kısmen donatılı veya sürekli donatılı beton plaklardan meydana gelir(Ağar, Sütaş, \& Öztaş, 1998) (Ağar et al., 1998).

Türkiye'de asfaltın ithal edilmesi, asfalt yolların bakım maliyetlerinin artması ve dışarı bağımlılıklar nedeni ile asfalt yollara alternatif olan beton yollar 1990'lı yılların başlarından itibaren ülkemizde kullanılmaya başlanmıştır. Esnek yollara alternatif olan beton yolların popülaritesi giderek artmış ve Avrupa ve Amerika'da olduğu gibi ülkemizde de beton yollar üzerine de önemli araştırmalar yapılmaya başlanmıştır.

Beton yolların servis ömrü dış faktörlere bağlı olup, bu faktörlerin birçoğu birbirleri ile ilişkilidir. Herhangi bir olumsuz faktörün ortaya çıkması diğer faktörleri de etkilediğinden olumsuzlukları da beraberinde getirmektedir. Örnek olarak ağır taşıt yüklerinin olduğu bir yolda yol kaplamasında oluşacak kırılmalar, betonda geçirimliliğin artmasına neden olacak, yol zemini ve temeli deformasyona uğrayarak kaplamada kırılmaların olmasına neden olacaktır (Bolat, Subaşi, Çullu, \& Akkaya, 2010).

Birçok avantajı olmasına rağmen, kırılgan bir malzeme olan beton, çatlama sonrası yorulma mukavemeti, aşınma direnci, eğilme mukavemeti, yük taşıma kapasitesi açısından genellikle zayıftır (Monteiro \& Mehta, 1993; Neville, 1995). Özellikle dinamik tekerlek yükleri, betonun köşe ve kenarlarında çatlaklara neden olmakta, düşük eğilme dayanımı ile bu çatlaklar kolayca yayılabilmektedir. Betona lif eklemek, betonun sünekliğini ve enerji yutma kapasitesini artırabilir (Lee, 2017; Lee, Cho, \& Choi, 2017). Rastgele ve eşit dağılımlı çelik lifler, betonda çatlak oluşumunu önemli ölçüde azaltır. Amerikan Beton Enstitüsü (ACI 544) beton matrisi içine çelik lif eklenmesinin, betonun tüm mekanik özelliklerini, özellikle de dayanıklılığı, çekme mukavemetini ve tokluğu arttırdığını bildirmiştir (Institute, 1986). Böylece, betonun sünme ve enerji yutma kapasitesi artarak süneklik düzeyi yüksek beton elde edilir.

\section{1. Çalışma Amacı}

Eğilmeye karşı zayıf olan beton yollara polipropilen (PP) lif katılarak iyileşmelerin görüldüğü literatürde mevcuttur (Haddad \& Smadi, 2004; Park \& Lee, 2004; Song, Hwang, \& Sheu, 2005; Toledo Filho \& Sanjuan, 1999). Bu çalışmada ise PP life benzer özellikleri ile atık malzeme olan kevların beton yollarda kullanılabilirliği araştırılmıştır.

Telekomünikasyon alanında kullanılan fiber optik kablolarda, kabloyu darbelere karşı korumak için kablo içerisinde kevlar olarak adlandırılan malzeme kullanılmaktadır (Şekil 1). Söz konusu malzeme endüstride zırh yapımındada kullanıldı̆̆ bilinen özellikle darbe dayanımını arttıran bir malzemedir. Fiber optik kabloların ekonomik ömrü 20 yıl civarındadır ve her yıl yaklaşı olarak 15 bin km kablo atık hale gelmektedir. PP lif gibi çok hafif bir malzeme olan Kevlar, atık hale gelen bu kabloların 1 km'sinde yaklaşık 5 kg kadar bulunmaktadır. Atık kevların ayrı bir kullanım alanı olmadığından ekonomiye tekrar kazandırılamamaktadır. Hem ekonomiye katkı sağlaması hem de doğaya tahribatının önlenmesi için atık kevların yol betonlarında kullanımı düşünülmüştür. Kevlar yerine yol betonlarında çatlakların önlenmesi için kullanılacak polipropilen lifler piyasadan alınan fiyatı yaklaşı olarak $30 \mathrm{TL} / \mathrm{kg}$ olup, $1 \mathrm{~km}$ kabloda 150 TL ekonomiye katkı sağlayacak lif çıkarılabilecektir. 15 bin km âtıl olacak kablo için yapılacak geri dönüşüm çalışmalar ile 2.250.000 TL ekonomiye katkı sağlayabilecektir. 


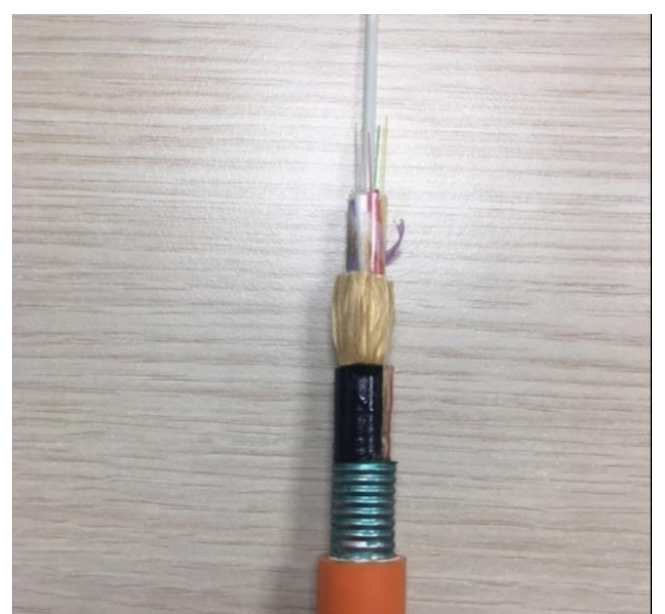

Şekil 1. Fiber optik kablo içerisinde kevlar

$\mathrm{Bu}$ amaçla, polipropilen lif ve kevlar ile üretilen yol betonlarının eğilme ve basınç mukavemeti ile elastisite modülü parametreleri incelenmiş̧ir. Her biri 3 seviyeli olmak üzere toplam 4 faktör (su/bağlayıcı oranı $(0.40,0.45,0.50)$, silis dumanı $(0, \% 5, \% 10)$, kevlar $(0,500 \mathrm{~g}, 1000 \mathrm{~g})$ polipropilen lif $(0,500 \mathrm{~g}, 1000 \mathrm{~g}))$, deney tasarımında göz önüne alınmıştır. Deneyler, tam faktöriyel deney tasarımına göre hem zaman hem de malzeme yönünden daha avantajlı olduğu düşünülen Taguchi Metoduna göre yapılmıştır (Peace \& Peace, 1993; Roy, 1990; Taguchi).

\section{Materyal ve Metot}

Çalışmada Erzurum Aşkale Çimento Fabrikasında üretilmiş olan ve TS EN 197-1 standartlarına uygun, CEM I 42.5 R çimentosu kullanılmıştır. CEM I 42.5 R çimentosunun kimyasal özellikleri Tablo 1'de, fiziksel ve mekanik özellikleri Tablo 2'de sunulmuştur.

Tablo 1. Çimentonun Kimyasal Analizi

\begin{tabular}{ll}
\hline Kimyasal Analizler & \\
\hline $\mathrm{SiO}_{2}$ & 18,10 \\
$\mathrm{Al}_{2} \mathrm{O}_{3}$ & 4,48 \\
$\mathrm{Fe}_{2} \mathrm{O}_{3}$ & 3,09 \\
$\mathrm{CaO}$ & 63,65 \\
$\mathrm{MgO}$ & 2,58 \\
$\mathrm{SO}_{3}$ & 2,84 \\
$\mathrm{~K}$ ızdırma kaybı & 3,90 \\
$\mathrm{~K}_{2} \mathrm{O}$ & 0,62 \\
$\mathrm{Na}_{2} \mathrm{O}$ & 0,21 \\
$\left(\mathrm{Na}_{2} \mathrm{O}\right) ; \mathrm{Na}_{2} \mathrm{O}+0,658 \times \mathrm{K}_{2} \mathrm{O}$ & 0,62 \\
$\mathrm{Cl}$ & 0,015 \\
Ölçülemeyen & 0,52 \\
$\mathrm{CaO}$ (sebest kireç) & 0,44 \\
Çözünmeyen kalınt & 0,55 \\
\hline
\end{tabular}

Tablo 2. Çimentonun Fiziksel ve Mekanik Özellikleri

\begin{tabular}{ll}
\hline Fiziksel ve mekanik testler \\
\hline İncelik $45 \mathrm{~m}$ elek üstü \% & 7,15 \\
Özgül ağılık $\left(\mathrm{g} / \mathrm{cm}^{3}\right)$ & 3,12 \\
Özgül yüzey $\left(\mathrm{cm}^{2} / \mathrm{g}\right)$ & 3698 \\
Piriz başı (Saat-dakika) & $2 \mathrm{sa}-31 \mathrm{dk}$ \\
Piriz sonu (Saat-dakika) & $3 \mathrm{sa}-11 \mathrm{dk}$ \\
Hacim genleşmesi (mm) & 1 \\
Basınç dayanımı 2 Gün (MPa) & 27,9 \\
Basıç dayanımı 28 Gün (MPa) & 58,0 \\
Su ihtiyacı (\%) & 29,5 \\
\hline
\end{tabular}


Polipropilen lifin teknik özellikleri Tablo 3'te verilmiştir.

Tablo 3. Polipropilen Lifin Teknik Özellikleri

\begin{tabular}{ll}
\hline Teknik Özelliği & Değer \\
\hline Saflı & \%100 polipropilen \\
Tip & Homopolimer \\
Katkı & Yok \\
Görünüm & Doğal Beyaz \\
Kesit & Dairesel \\
Standart & ASTM-C1116 \\
Fiber uzunluğu & $6,12 \mathrm{~mm}$ \\
Çekme mukavemeti & $350 \mathrm{MPa}$ \\
Özgül Yoğunluk & 0.91 gr/cm ${ }^{3}$ \\
Yumuşama noktası & $140^{\circ} \mathrm{C}$ \\
Ergime noktası & $165-170{ }^{\circ} \mathrm{C}$ \\
Asit etkisi & Dayanıklı \\
Oksidasyon direnci & Çok iyi \\
Organic çözücü etkisi & Dayanıklı \\
Biyolojik direnç & Çok iyi \\
Alkali etkisi & Dayanıklı \\
UV direnci & Evet \\
Açınma dayanımı & Çok iyi \\
Nem tutma & Sıfir \\
\hline
\end{tabular}

Kevların lifin fiziksel özellikleri Tablo 4’te verilmiştir.

Tablo 4. Kevlar Lifin Teknik Özellikleri

\begin{tabular}{lll}
\hline Elyaf tipi & Aramid & HM \\
\hline Lineer Yoğunluk & Dtex & 3160 \\
Sizing oranı & $\%$ & 0,8 \\
Kopmadaki uzama & $\%$ & 2,5 \\
Çekme Dayanımı & $\mathrm{MPa}$ & 2926 \\
Çekme Kuvveti & $\mathrm{N}$ & 325 \\
Elastisite Modulu & $\mathrm{GPa}$ & 110 \\
Yanıcılık & LOI- & 0,29 \\
Sicak hava büzüşmesi & Index & 0,1 \\
$\left(15\right.$ min at $\left.190^{\circ} \mathrm{C}\right)$ & & \\
Sicaklık Mukavemeti & $\%$ & 90 \\
$\left(48 \mathrm{~h}\right.$ at $\left.200^{\circ} \mathrm{C}\right)$ & & \\
Bozulma sicaklığ & $\mathrm{C}$ & $>450$ \\
Termal genleşme Kts. & $109 \mathrm{~K}$ & $-3,5$ \\
\hline
\end{tabular}

Bağlayıcıdaki mikro boşlukların doldurulabilmesi için puzolonik malzemeler kullanılmaktadır. Bu malzemeler, puzolonik reaksiyonları sayesinde bağlayıcının mukavemetine katkıda bulunur (Chan \& Chu, 2004; Hınıslığlu \& Bayrak, 2004; Richard \& Cheyrezy, 1995). Dolayısıyla çalışmada çimentoya ek olarak silis dumanı kullanılmıştır. Silis dumanının teknik özellikleri Tablo 5 'te verilmiştir. 
Tablo 5. Silis Dumanı Teknik Özellikleri

\begin{tabular}{ll}
\hline Şekilsiz $\mathrm{SiO}_{2}$ & $\min \% 93$ (gerçek \%96,1) \\
$\mathrm{H} 20($ nem) & $\max \% 0,3$ (gerçek \%0,19) \\
Kızdırma Kayb1 & (L.O.I max \%3,5) (gerçek \%1,81) \\
+45 mikron üzeri & $\max \% 2.5($ gerçek \%0,58) \\
Hacim Yoğunluğu & $0,55-0,65 \mathrm{~kg} / \mathrm{dm}^{3}(\mathrm{D})$ \\
BET & min. $15-28 \mathrm{~m} 2 /$ gr $($ gerçek $23,36 \mathrm{~m} 2 / \mathrm{gr})$ \\
\hline
\end{tabular}

Çalışmada dökülen numune betonlarında GCP Applied Technologies firması tarafından üretilen ZYLA 645 Süperakışkanlaştırıcı beton katkısı kullanılmıştır. Söz konusu katkı maddesi, kullanıma hazır akışkanlaştırıcı beton katkısıdır. Betonun nihai özelliklerine önemli etkileri bulunan hidroksile organik bileşenlerin sulu çözeltisidir. Öngörülen performansı standart olarak sağlayacak şekilde etkin kontrol altında üretilir. Kalsiyum klorür içermez. TS EN 934-2 özelliklerine uygundur.

Kullanılan kırmataş agrega, Erzincan ili sınırları içerisindeki Tercan ilçesi yakınlarındaki Aşkale Çimentoya ait agrega üretimi için kurulan tesisten temin edilmiştir. Kullanılan agrega kırmataş malzeme olup max. dane çapı $32 \mathrm{~mm}$ dir. Agrega temini sırasında yıkanmış olup, karışımın granülometri eğrisi, Tablo 6'da verilmiştir.

Tablo 6. Agrega Karışım Sonrası Elek Analizi.

\begin{tabular}{cc}
\hline Elek $(\mathbf{m m})$ & Geçen (\%) \\
\hline $\mathbf{0 , 2 5}$ & 7.50 \\
$\mathbf{0 , 5}$ & 11.78 \\
$\mathbf{1}$ & 18.21 \\
$\mathbf{2}$ & 29.89 \\
$\mathbf{4}$ & 46.75 \\
$\mathbf{8}$ & 61.13 \\
$\mathbf{1 6}$ & 78.48 \\
$\mathbf{3 2}$ & 100 \\
\hline
\end{tabular}

\subsection{Deneysel Yaklaşım}

Geleneksel deney tasarımında, bir faktör değiştirilirken diğer bütün faktörler sabit tutulur. Deney tasarımındaki faktör ve seviyeler arttıkça yapılacak deney sayısı da artacaktır. Dolayısıyla böyle bir tasarımın pratikte yapılması malzeme, zaman ve işçilik açısından zorlukları da beraberinde getirecektir. Aynı zamanda, faktörler arasında iç etkileşimin olması durumunda, geleneksel deney tasarımına göre bulunan optimum şartlar, gerçek optimum şartlar olmayabilir. Deney tasarım tekniklerinden biri olan Taguchi Metodu sistematik dizaynlarda optimizasyon için başarılı bir şekilde uygulanmaktadır (Bayrak \& Hınıslıŏlu, 2017; Hınıslıoğlu \& Bayrak, 2004, 2005; Joshaghani, Ramezanianpour, Ataei, \& Golroo, 2015).

$\mathrm{Bu}$ yöntem performans ve kalite tasarımlarını optimize etmek için sistematik bir yaklaşım sağlar. Taguchi yöntemi kullanılarak yapılacak optimizasyonlar 8 adımda gerçekleştirilir.

1. Değerlendirilecek parametrelerin belirlenmesi

2. Bu parametrelere ait seviyelerin ve mümkün olan iç etkileşimlerin belirlenmesi

3. Uygun orthogonal dizisinin belirlenmesi

4. Ortogonal diziye dayanarak deney sonuçlarının metoda uyarlanması

5. Performans istatistiklerinin hesaplanmas1

6. Performans karakteristikleri kullanılarak sonuçların varyans analizi ile değerlendirilmesi

7. Optimum seviyelerin seçilmesi

8. Sonuçların doğrulanması

Taguchi yönteminde optimizasyon kriteri olarak performans istatistiği $(\mathrm{S} / \mathrm{N})$ kullanılmaktadır. En büyük - en iyi, nominal - en iyi ve en küçük - en iyi olmak üzere üç çeşit performans istatistiği vardır. Deneylerden elde edilen veriler kullanılarak S/N değerleri, en büyük en iyi (the bigger the better) performans istatistiği baz alınarak (2.1) eşitliğine göre hesaplanmıştır.

$$
\frac{S}{N_{L}}=-10 \log \left[\frac{1}{n} \sum_{1}^{n} \frac{1}{Y_{i}^{2}}\right]
$$

Burada; 
$\mathrm{S} / \mathrm{NL} \quad$ : Performans istatistiği

n : Bir deney kombinasyonunda yapılan tekrar sayıs1

$\mathrm{Y} i: i$. deneyin performans istatistiğidir.

SNL'yi maksimum yapan parametre seviyeleri optimumdur. Ancak Taguchi Metoduna optimum parametre seviyelerini veren deney yapılmamış olabilir. Dolayısıyla optimum şartlara karşılık gelen performans değeri eşitlik (2.2) yardımıyla tahmin edilebilir.

$\mathrm{Yt}=\mu+\mathrm{X}_{i}+\mathrm{e} i$

Burada;

$\mu$ : Performans değerinin genel ortalaması,

$\mathrm{X}_{i}$ : Deneydeki parametre-seviye kombinasyonun sabit etkisidir.

$\mathrm{e}_{i} \quad$ : i. deneydeki rastsal hata

Deneysel sonuçlara bağlı olarak hesaplanan bu $Y_{t}$ değeri bir nokta tahminidir. Dolayısıyla yapılan doğrulama deneylerinin sonuçlarının anlamlı olup olmadıklarını belirleyebilmek için belirli bir hata seviyesinde güven aralığı oluşturulmalıdır. Seçilen hata seviyesindeki güven aralı̆̆ ise,

$\mu \mp \sqrt{F_{\alpha ; 1 ; D F_{M S e}} M S_{e}\left[\frac{1+m}{N}+\frac{1}{n_{i}}\right]}$

bağıntısıyla hesaplanır (Peace \& Peace, 1993; Roy, 1990; Taguchi).

Burada;

F : Tablo değeri,

$\alpha \quad$ : Hata seviyesini,

$\mathrm{DF}_{\mathrm{Mse}}$ : Hata kareler ortalamasının serbestlik derecesi toplamını,

$\mathrm{m}$ : Ortalama tahmininde kullanılan parametrelerin serbestlik dereceleri

$\mathrm{n}_{i} \quad$ : Yapılan doğrulama deneylerinin tekrar sayısını göstermektedir (Roy, 1990; Taguchi).

Çalışmada, Așkale Çimento Fabrikasında üretilmiş CEM I 42,5 R tipi çimento, Aşkale Çimento Tercan tesislerinde üretilen kırmataş agrega ana birleşenler olarak kullanılmıştır. Dost Kimya firmasından temin edilmiş PP lif, Türk Telekom AŞ. tarafından hurdaya verilen kablolardan temin edilen Kevlar lif, silis dumanı (SD) ve ZYLA 645 süper akışkanlaştırıcı beton katkısı kullanılmıştır. Beton karışımında gerekli olan su için içme suyu kullanılmıştır. Çimento dozajı sabit tutulmuş, SD, su/bağlayıcı oranı, PP lif ve kevlar lif miktarı değişken olarak belirlenmiştir.

Yol betonları için çimento dozajının, 2016 yılında çıkan beton yol kaplamaları teknik şartnamesine (Müdürlüğü, 2016) göre 300 $\mathrm{kg} / \mathrm{m}^{3}$ 'ten büyük olması önerilmektedir. Dolayısıyla, çimento dozaj1 $350 \mathrm{~kg} / \mathrm{m}^{3}$ olarak belirlenmiş, silis dumanı ise çimento yerine çimento ağırlı̆̆ının $\% 0, \% 5$ ve $\% 10$ oranlarında katılarak kullanılmıştır. Polipropilen ve Kevlar lif $0 \mathrm{~g} / \mathrm{m}^{3}, 500 \mathrm{~g} / \mathrm{m}^{3}, 1000 \mathrm{~g} / \mathrm{m}^{3}$ oranında kullanılmıştır. Akışkanlaştıııcı kimyasal katkı tüm numuneler için sabit tutularak \%1.5 oranında kullanılmıştır. Tüm faktörler dikkate alınarak toplam 9 grup numune hazırlanmıştır. Kullanılan parametre ve seviyeleri Tablo 7'de, bu parametreler dikkate alınarak L9 ortogonal dizisine göre yapılan deney planı ise Tablo 8'de gösterilmiştir (Tunçel, 2018).

Tablo 7. Parametre ve Seviyeleri

\begin{tabular}{lccc}
\hline \multirow{2}{*}{ Parametreler } & \multicolumn{3}{c}{ Seviyeler } \\
\cline { 2 - 4 } (A) su/bağlayıc1 oran1 & $0.40(\mathbf{A} 1)$ & $0.45(\mathbf{A} 2)$ & $0.50(\mathbf{A 3})$ \\
(B) SD (\%) & $0.00(\mathbf{B} 1)$ & $5.00(\mathbf{B 2})$ & $10.00(\mathbf{B 3})$ \\
(C) Kevlar $\left(\mathrm{g} / \mathrm{m}^{3}\right)$ & $0.00(\mathbf{C 1})$ & $500(\mathbf{C 2})$ & $1000(\mathbf{C 3})$ \\
(D) PP Lif $\left(\mathrm{g} / \mathrm{m}^{3}\right)$ & $0.00(\mathbf{D 1})$ & $500(\mathbf{D 2})$ & $1000(\mathbf{D 3})$ \\
\hline
\end{tabular}


Tablo 8. Deney Planı

\begin{tabular}{ccccc}
\hline $\begin{array}{c}\text { Grup } \\
\text { No }\end{array}$ & su/bağlayıcı & SD & $\begin{array}{c}\text { Kevlar } \\
\left(\mathbf{g} / \mathbf{m}^{\mathbf{3}}\right)\end{array}$ & $\begin{array}{c}\text { PP Lif } \\
\left(\mathbf{g} / \mathbf{m}^{\mathbf{3}}\right)\end{array}$ \\
\hline 1 & $\mathrm{~A} 1$ & $\mathrm{~B} 1$ & $\mathrm{C} 1$ & $\mathrm{D} 1$ \\
2 & $\mathrm{~A} 1$ & $\mathrm{~B} 2$ & $\mathrm{C} 2$ & $\mathrm{D} 2$ \\
3 & $\mathrm{~A} 1$ & $\mathrm{~B} 3$ & $\mathrm{C} 4$ & $\mathrm{D} 3$ \\
4 & $\mathrm{~A} 2$ & $\mathrm{~B} 1$ & $\mathrm{C} 2$ & $\mathrm{D} 3$ \\
5 & $\mathrm{~A} 2$ & $\mathrm{~B} 2$ & $\mathrm{C} 3$ & $\mathrm{D} 1$ \\
6 & $\mathrm{~A} 2$ & $\mathrm{~B} 3$ & $\mathrm{C} 1$ & $\mathrm{D} 2$ \\
7 & $\mathrm{~A} 3$ & $\mathrm{~B} 1$ & $\mathrm{C} 3$ & $\mathrm{D} 2$ \\
8 & $\mathrm{~A} 3$ & $\mathrm{~B} 2$ & $\mathrm{C} 1$ & $\mathrm{D} 3$ \\
9 & $\mathrm{~A} 3$ & $\mathrm{~B} 3$ & $\mathrm{C} 2$ & $\mathrm{D} 1$ \\
\hline
\end{tabular}

Karışımdaki malzeme miktarları, karışıma ağırlık olarak konularak deney numuneleri üretilmiştir. Belirtilen karışım oranları ile dökülen numuneler 28 gün boyunca su küründe bekletilmiştir. Piriz alan numuneler su küründen alınmış, 1 gün kurumaya bırakılmış ve Atatürk Üniversitesi İnşaat laboratuvarında bulunan BESMAK marka Test Makinaları ile elastisite modülü, basınç ve eğilme mukavemetleri belirlenmiştir.

\section{Araştırma Sonuçları ve Tartışma}

Ele alınan parametre ve bunların seviyelerine göre (Tablo 7 ve 8) yapılan deneylerden elde basınç ve eğilme mukavemetleri ile elastisite modülü sonuçları Tablo 9'da verilmiştir. Bu tabloda, deneylerden elde edilen üç numunenin ortalaması hem MPa cinsinden hem de eşitlik (1) yardımıyla hesaplanan S/N değerleri ile verilmiştir (Tunçel, 2018). Taguchi Yöntemi'ne göre, optimum şartların belirlenebilmesi için ortalama $\mathrm{S} / \mathrm{N}$ etkilerinin hesaplanması gerekmektedir. S/N değerleri eşitlik (1) yardımıyla hesaplandıktan sonra bu değerler kullanılarak ortalama S/N değerleri hesaplanmış ve Tablo 10, 12 ve 14'te verilmiştir. Bu tablolarda her faktörün maksimum değeri, o faktörün optimum seviyesini vermektedir. Tablolarda verilen değerlerin daha iyi anlaşılabilmesi için, bu değerler yardımıyla elde edilen optimum durum grafik olarak Şekil 2,3 ve 4'te verilmiştir. Daha sonra varyans analizi kullanılarak parametrelerin basınç ve eğilme mukavemeti ile elastisite modülü üzerine olan katkıları hesaplanmış ve Tablo 11, 13 ve 15 'te verilmiştir.

Tablo 9. Deney Sonuçları

\begin{tabular}{|c|c|c|c|c|c|c|}
\hline \multirow[t]{2}{*}{ Grup No } & \multicolumn{2}{|c|}{$\begin{array}{c}\text { Basınç } \\
\text { Mukavemeti }\end{array}$} & \multicolumn{2}{|c|}{$\begin{array}{c}\text { Eğilme } \\
\text { Mukavemeti }\end{array}$} & \multicolumn{2}{|c|}{$\begin{array}{l}\text { Elastisite } \\
\text { Modülü }\end{array}$} \\
\hline & (Mpa) & $\mathrm{S} / \mathrm{N}$ & (MPa) & $\mathrm{S} / \mathrm{N}$ & $(\mathrm{GPa})$ & $\mathrm{S} / \mathrm{N}$ \\
\hline 1 & 51.10 & 34.169 & 6,21 & 15,860 & 3,01 & 9,575 \\
\hline 2 & 60.40 & 35.620 & 5,71 & 15,126 & 3,90 & 11,817 \\
\hline 3 & 55.95 & 34.956 & 5,83 & 15,306 & 4,27 & 12,612 \\
\hline 4 & 51.16 & 34.409 & 6,73 & 16,562 & 3,94 & 11,916 \\
\hline 5 & 59.99 & 35.562 & 5,60 & 14,961 & 4,00 & 12,030 \\
\hline 6 & 62.86 & 35.968 & 7,67 & 17,701 & 5,55 & 14,886 \\
\hline 7 & 52.67 & 33.328 & 6,05 & 15,633 & 4,01 & 12,059 \\
\hline 8 & 48.58 & 33.729 & 4,64 & 13,338 & 3,54 & 10,974 \\
\hline 9 & 55.70 & 34.918 & 6,52 & 16,290 & 6,61 & 16,404 \\
\hline Ortalama & & 34.740 & & 15.642 & & 12.475 \\
\hline
\end{tabular}

\subsection{Basınç Mukavemeti Sonuçları}

Şekil 2 incelendiğinde, beton içerisindeki karışım oranlarına göre optimum seviyelerin A2, B3, C2, D2 olduğu görülmüştür. Tablo 11 incelendiğinde, basınç mukavemeti üzerine en büyük etkisi olan parametrenin sırasıyla su/bağlayıcı oranı, SD oranı, kevlar lif oranı ve PP lif oranı olduğu görülmektedir. Tablo 8'de verilmiş olan deney planı incelendiğinde, optimum değerleri veren tasarımın deney planında bulunmadığ1 görülmektedir. Sonucun doğruluğunun test edilmesi için ilgili parametre değerlerine göre (A2, B3, C2, D2) numune hazırlanarak 28 gün kür koşulları ardından tekrar kırılmıştır. Yapılan doğrulama deneyi sonucunda 69,26MPa basınç dayanımı elde edilmiştir. Bu sonuca karşılık gelen $\mathrm{S} / \mathrm{N}$ değeri 36,81'dir. \%95 güven seviyesinde bu değerin 32,078 ile 40,578 arasında olması gerekmektedir (Tablo 11). Söz konusu değerin \%95 güven aralığında doğru olduğu görülmüştür. 


\begin{tabular}{lcccc}
\hline & Su/Bă̆. & SD & Kevlar & PP Lif \\
\hline 1. Seviye & $34,915(A 1)$ & $33,969(B 1)$ & $34,622(C 1)$ & $34,883(D 1)$ \\
2.Seviye & $35,313(A 2)$ & $34,970(B 2)$ & $34,982(C 2)$ & $34,972(D 2)$ \\
3.Seviye & $33,992(A 3)$ & $35,281(B 3)$ & $34,615(C 3)$ & $34,365(D 3)$ \\
\hline
\end{tabular}

Tablo 11. Performans Tahminleri

\begin{tabular}{lcc}
\hline Faktörler & Seviye & S/N'e olan katkısı \\
\hline Su/Bağ & A2 & 0.573 \\
SD & B3 & 0.541 \\
Kevlar & C2 & 0.242 \\
PP Lif & D2 & 0.232 \\
\hline Tüm Faktörlerin Katkısı (S/N) & 1.588 \\
Ortalama Performans İstatistiği (S/N) & 34.740 \\
Optimum Şartlarda Beklenen Değer (S/N) & 36.328 \\
Doğrulama Deneyi Sonucu (S/N) / (MPa) & $36.81 / 69.26$ \\
Güven Aralığ $(\alpha=95 \%)(\mathrm{S} / \mathrm{N})$ & $32.078-40.5781$ \\
\hline
\end{tabular}

Sonuçlar incelendiğinde, 28 günlük basınç mukavemetinin su/bağlayıcı oranının 2. seviyesinde, SD'ının 3. seviyesinde, Kevlar oranının 2. seviyesinde ve PP lif oranının 2. seviyesinde elde edildiği görülmektedir. Basınç deneylerinde, parametrelerin mukavemet üzerine etkileri Şekil 2'de gösterilmiştir.

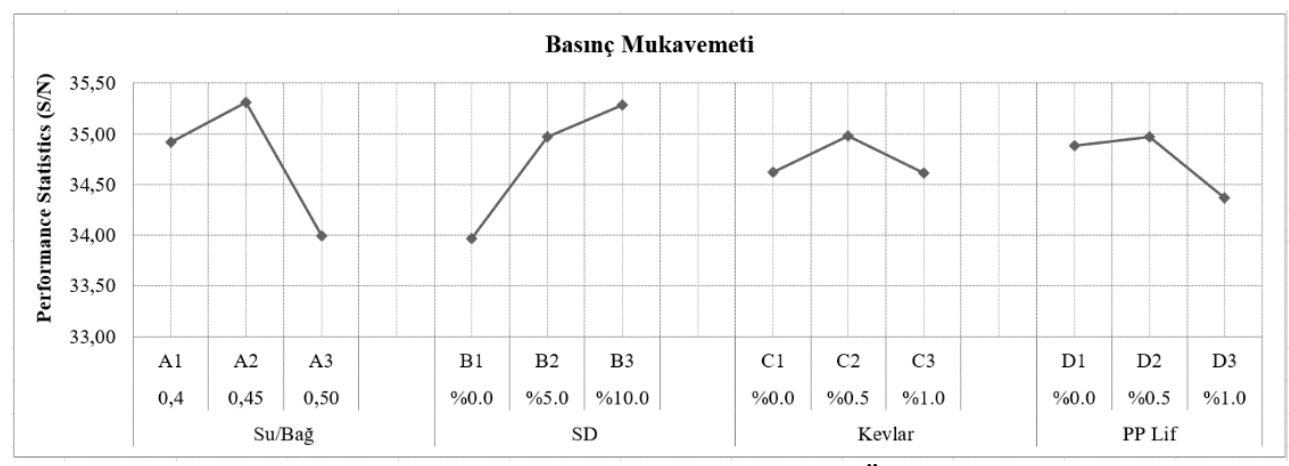

Şekil 2. Parametrelerin Basınç Mukavemeti Üzerine Etkisi

\subsection{Eğilme Mukavemeti Sonuçları}

Tablo 12. Eğilme Mukavemeti Için Ortalama S/N Etkileri

\begin{tabular}{lcccc}
\hline & Su/Bağ & SD & Kevlar & PP Lif \\
\hline 1. Seviye & $15,431(A 1)$ & $16,018(B 1)$ & $15,633(C 1)$ & $15,704(D 1)$ \\
2.Seviye & $16,408(A 2)$ & $14,475(B 2)$ & $15,993(C 2)$ & $16,153(D 2)$ \\
3.Seviye & $15,087(A 3)$ & $16,432(B 3)$ & $15,300(C 3)$ & $15,069(D 3)$ \\
\hline
\end{tabular}

Yapılan eğilme deneylerinden elde edilen sonuçlara göre (Şekil 3), eğilme mukavemetini maksimum yapan parametre seviyelerinin yani optimum durumunun A2, B3, C2, D2 olduğu görülmüştür. Tablo 13 incelendiğinde, eğilme mukavemetine etki eden en büyük parametrenin SD olduğu, bunu sırasıyla, su/bağlayıcı oranı, PP lif oranı ve Kevlar lif oranının izlediği görülmektedir. Tablo 8'de verilen deney planına bakıldığında, maksimum eğilme mukavemetini veren kombinasyonun deney tasarımında bulunmadığı görülmektedir. Sonucun doğruluğunun test edilmesi için ilgili parametre değerlerine (A2, B3, C2, D2) göre numune hazırlanarak 28 gün kür koşulları ardından tekrar kırılmıştır. Yapılan doğrulama deneyi sonucunda $8.45 \mathrm{MPa}$ eğilme mukavemeti elde edilmiştir. Bu sonuca karşılık gelen $\mathrm{S} / \mathrm{N}$ değeri 18.54 'tür. \%95 güven seviyesinde bu değerin 17.346 ile 18.774 arasında olması gerekmektedir. Söz konusu değerin \%95 güven aralığında doğru olduğu görülmüştür. 
Avrupa Bilim ve Teknoloji Dergisi

Tablo 13. Performans Tahminleri

\begin{tabular}{lcc}
\hline Parametreler & Seviye & S/N'e olan Katkısı \\
\hline Su/Bağ & A2 & 0.766 \\
SD & B3 & 0.790 \\
Kevlar & C2 & 0.351 \\
PP Lif & D2 & 0.511 \\
\hline Tüm Faktörlerin Katkısı (S/N) & 2.418 \\
Ortalama Performans İstatistiği (S/N) & 15.642 \\
Optimum Şartlarda Beklenen Değer $(\mathrm{S} / \mathrm{N})$ & 18.060 \\
Doğrulama Deneyi Sonucu $(\mathrm{S} / \mathrm{N}) /(\mathrm{MPa})$ & $18.54 / 8.45$ \\
Güven Aralığı $(\alpha=95 \%)(\mathrm{S} / \mathrm{N})$ & $17.346-18.774$ \\
\hline
\end{tabular}

Sonuçlara incelendiğinde, 28 günlük eğilme mukavemetlerinde, su/bağlayıcı oranının 2. seviyesinde, SD'ının 3. seviyesinde, Kevlar oranının 2. seviyesinde ve PP lif oranının 2. seviyesinde maksimum mukavemetin elde edildiği görülmektedir. Farklı karışım oranlarındaki her bir numune grubu üzerinde yapılan eğilme deneylerinde, parametrelerin mukavemet üzerine etkileri Şekil 2, 3 ve 4'de gösterilmiştir.

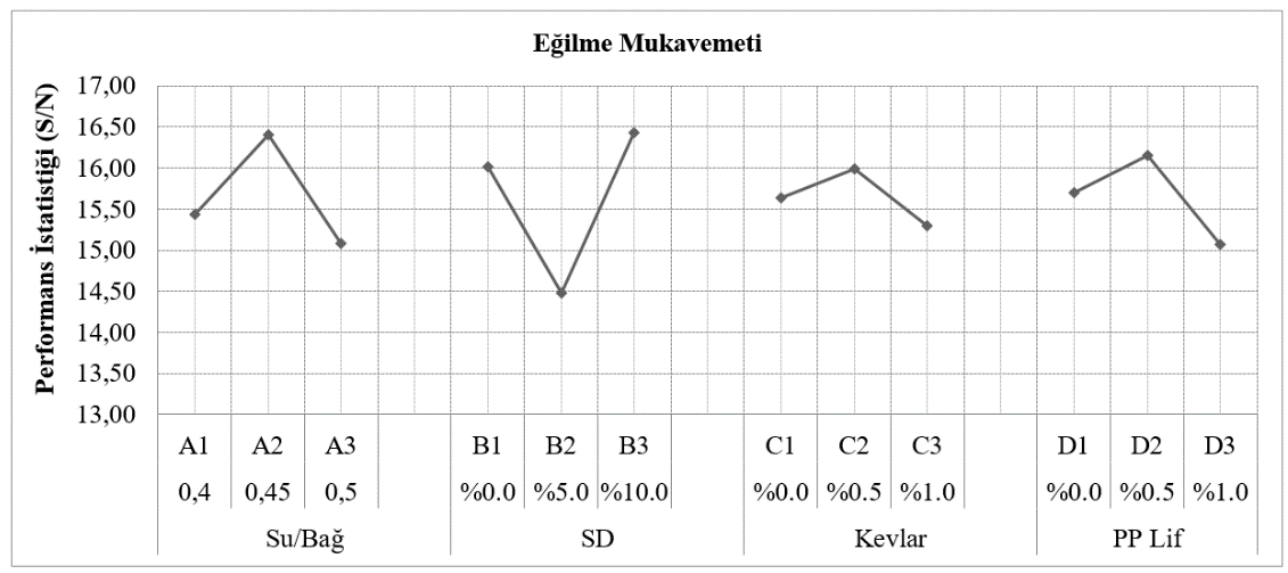

Şekil 3. Parametrelerin Eğilme Mukavemeti Üzerine Etkisi

\subsection{Elastisite Modülü Deneyi Sonuçları}

Tablo 14. Elastisite Modülü Için Ortalama S/N Etkileri

\begin{tabular}{lcccc}
\hline & Su/Băg & SD & Kevlar & PP Lif \\
\hline 1. Seviye & $11,335(A 1)$ & $11,183(B 1)$ & $11,812(C 1)$ & $12,670(D 1)$ \\
2.Seviye & $12,944(A 2)$ & $11,607(B 2)$ & $13,379(C 2)$ & $12,921(D 2)$ \\
3.Seviye & $13,146(A 3)$ & $14,634(B 3)$ & $12,234(C 3)$ & $11,834(D 3)$ \\
\hline
\end{tabular}

Yapılan elastisite deneylerinden elde edilen sonuçlara göre, elastisite modülünü maksimum yapan parametre seviyelerinin A3, B3, C2, D2 olduğu görülmüş̧ür. Elastisite modülüne en büyük etkinin silis dumanı olduğu, bunu sırasıyla, Kevlar lif oranı, su/bağlayıc1 oranı ve Polipropilen lif oranı olduğu belirlenmiştir. Tablo 8'de verilen deney planlarına bakıldığında sonuçlarda ulaştı̆̆ımız optimum değerlerdeki tasarımın bulunmadığı görülmektedir. Sonucun doğruluğunun test edilmesi için ilgili parametre değerlerine göre numune hazırlanarak 28 gün kür koşulları ardından tekrar kırılmıştır. Yapılan deneyler sonucunda 6,17 GPa elastisite modülü değeri elde edilmiştir. Bu sonuca karşıllık gelen S/N değeri 15,806'dır. \%95 güven seviyesinde bu değerin 15,492 ile 17,818 arasında olması gerekmektedir. Söz konusu değerin \%95 güven aralığında doğru olduğu görülmüştür. 
European Journal of Science and Technology

Tablo 15. Performans Tahminleri

\begin{tabular}{lcc}
\hline Parametreler & Seviye & S/N'e olan Katkısı \\
\hline Su/Bağ & A3 & 0.671 \\
SD & B3 & 2.159 \\
Kevlar & C2 & 0.904 \\
PP Lif & D2 & 0.446 \\
\hline Tüm Faktörlerin Katkısı $(\mathrm{S} / \mathrm{N})$ & 4.180 \\
Ortalama Performans İstatistiği (S/N) & 12.475 \\
Optimum Şartlarda Beklenen Değer $(\mathrm{S} / \mathrm{N})$ & 16.655 \\
Doğrulama Deneyi Sonucu $(\mathrm{S} / \mathrm{N}) /(\mathrm{GPa})$ & $15.81 / 6.17$ \\
Güven Aralı̆̆ı $(\alpha=95 \%)(\mathrm{S} / \mathrm{N})$ & $15.492-17.818$ \\
\hline
\end{tabular}

28 günlük elastisite modülünü maksimum yapan parametre seviyeleri, su/bağlayıcı oranının 3. seviyesi, silis dumanının 3. seviyesi, Kevlar oranı 2. Seviyesi ve polipropilen lif oranının 2. seviyesidir. Farklı karışım oranlarındaki her bir numune grubu üzerinde yapılan elastisite modülü deneylerinde, parametrelerin mukavemet üzerine etkileri Şekil 4’te gösterilmiştir.

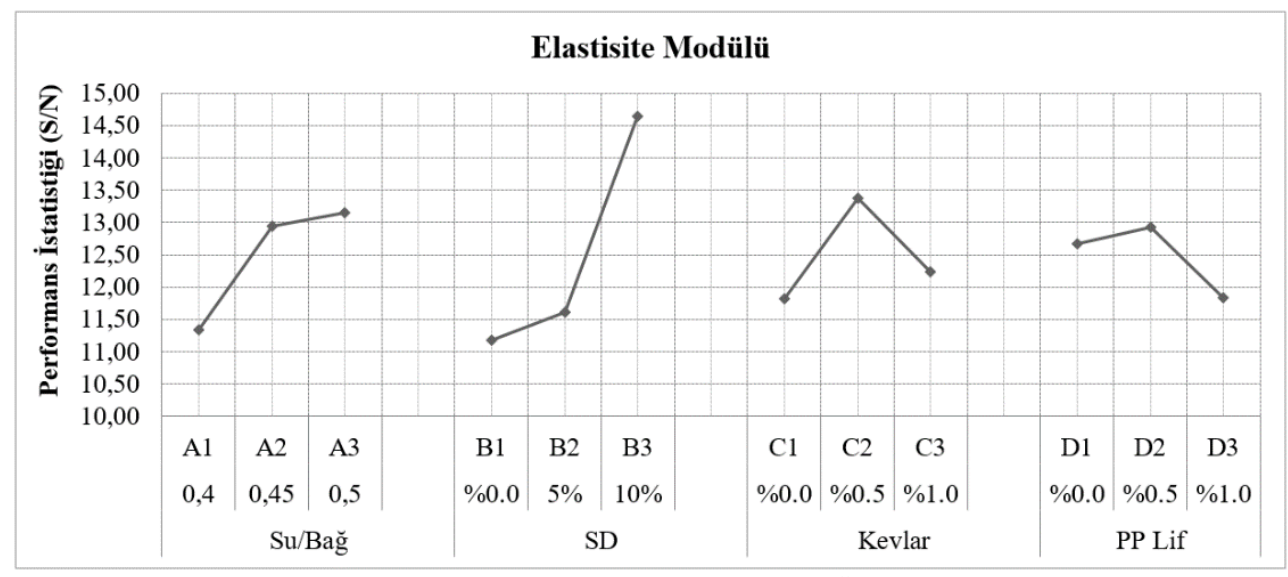

Şekil 4. Parametrelerin Elastisite Modülü Üzerine Etkileri

\section{Sonuç}

Dünyada ve ülkemizde beton yol kullanımı gün geçtikçe artmaktadır. Beton yolların asfalt yollara oranla dışa bağımlılığının olmaması, taşıma kapasitelerinin yüksek olması ve bakım masraflarının düşük olması nedeni ile tercih edilmektedir. Genel olarak, çok yüksek trafik hacmine sahip ve ağır taşıt trafiğinin yüksek olduğu karayollarında, otoban ve havaalanlarında kullanılmaktadır. Yol kaplaması olarak betonun görevi, araçlardan gelen dingil yüklerini tabana iletmek ve bu durumda taban zemininin deforme olmamasını sağlamaktır. Beton yol üzerinden geçen bir tekerlek yükü, beton plak üzerinde basınç, eğilme ve çekme gerilmeleri oluşturmaktadır. Beton yapısı gereği basınca dayanıklı olsa da eğilmeye karşı zayıf bir malzemedir. Betonun eğilme dayanımının arttırılması için birçok çalışma yapılmış ve yapılmaya devam edilmektedir. Bu çalışmada ise hem ekonomik bir değeri olmayan kevlar malzemesinin ekonomiye tekrar kazandırılması hem de lifli bir yapısı sayesinde betonun eğilme dayanımının arttırılması hedeflenmiştir. Bunun için lifli diğer bir malzeme olan ve literatürde üzerinde çalışmalar yapılmış olan polipropilen lif ile birlikte kullanılması irdelenmiştir. Silis dumanı ve su/bağlayıcı oranı ise diğer parametreler olarak çalışmada kullanılmıştır. Deney tasarımı olarak Taguchi Metodu kullanılmıştır. Yapılan çalışma sonucunda aşağıdaki sonuçlara varılmıştır.

- Basınç mukavemetinin maksimum değeri (optimum şartlarda) $69 \mathrm{MPa}$ ile $\% 5$ kevlar ve \%5 PP lif kullanılması durumunda bulunmuştur.

- $\% 5$ kevlar oranından \%10 kevlar oranına çıkıldığında mukavemetin düştüğü görülmüştür. Bu oranın düşmesine beton içerisine katılan polipropilen lif ile birlikte kullanılması da etkili olmuştur. Optimum mukavemette $\% 10$ oranında lif kullanılmıştır.

- Gerek eğilme mukavemeti gerek basınç mukavemeti gerekse de elastisite modülü değerlerinde, lif oranın \%10'un üzerine çıkması durumunda düşüşler tespit edilmiştir.

- Su/Bağlayıcı oranının optimum seviyesi basınç ve eğilme de 2. seviyede, elastisite modülünde ise 3. Seviyede sağlandığı belirlenmiştir.

- Silis dumanı basınç, eğilme ve elastisite modüllerinin tamamında optimum değeri 3. seviyesinde sağlamıştır. Silis dumanı işlenebilirliği ideal seviyeye gelmesinden sonra betona katkısı yüksek oranda olmuştur.

- Optimum durumda polipropilen lif oranının hem eğilme mukavemeti hem basınç mukavemeti hem de elastisite modülü için 2. seviyesinde sağlamıştır. \%5 oranında poliprobilen lif ve $\% 5$ oranında kavlar’ın kullanılması kontrol betonuna oranla daha yüksek mukavemetler sağlamıştır. 
- Yapılan Taguchi istatistiğine göre, Kevlar tek başına kullanıldığında (PP lif ve SD olmadan) sırasıyla 6.47 ve 52.80 MPa'lık bir eğilme ve basınç mukavemetlerine sahip olacağı öngörülmektedir.

- Elastisite modülü ve eğilme mukavemetinde en etkin parametrenin silis dumanı olduğu görülmüştür.

- Kevlar, elastiste modülünde ve basınç dayanımında polipropilene oranla daha etkin bir malzeme olmuştur. Polipropilen lif yerine betonda ekonomik olarak bir değeri olmayan atık kevların kullanılması hem ekolojiye hem de ekonomiye katkı sağlayacaktır.

- Su/bağlayıcı oranı sadece basınç dayanımında en etkin parametre olarak görülmüsştür.

- Kevlar, genel olarak yol betonunun gerek basınç dayanımına gerek eğilme dayanımına gerekse de elastisite modülüne olumlu katkıda bulunduğu gözlemlenmiş̧tir. Bununla birlikte polipropilen life göre basınç mukavemeti ve elastisite modülünde daha etkin bir parametre olduğu görülmüştür.

- Beton içerisinde polipropilen lif yerine kevlar kullanılmasının, polipropilen lifin kg fiyatının $30 \mathrm{TL}$ olduğu düşünüldüğünde, $1 \mathrm{~km}$ kabloda 150 TL ekonomiye katkı sağlayacak lif çıkarılabilecektir. 15 bin km âtıl olacak kablo için yapılacak geri dönüşüm çalışmalar ile 2.250.000 TL ekonomiye katkı sağlayabilecektir.

- Kevlar ile üretilen yol betonlarının tasarımında Taguchi Metodunun kullanılabilirliği, sonuçların mevcut literatürle örtüşmesi neticesinde söylenebilir.

Yapılan deneysel çalışmalarda beton numunelerinde 3 farklı Su/bağlayıcı oranında, 3 farklı silis dumanı oranında, 3 farklı polipropilen lif oranında ve yine 3 farklı Kevlar lif oranında çalışmalar yapılmış olup, sonraki çalışmalarda kevlar için farklı karışım oranlarında farklı dayanımlar test edilebilir. Aynı zamanda, bu çalışmada kevlar betonun içerisine 4 cm'lik parçalar halinde katılmıştır. Bunun yerine beton içeresine farklı boyutlarda katılarak boyut etkisi de incelenebilir.

\section{Kaynakça}

Ağar, E., Sütaş, İ., \& Öztaş, G. (1998). Beton yollar: rijit yol üstyapıları; malzeme-tasarım-üretim-yapım-bakım teknikleri: İstanbul Teknik Üniversitesi.

Bayrak, O. Ü., \& Hınıslıoglu, S. (2017). A new approach to the design of rigid pavement: single-axle loading. Road Materials and Pavement Design, 18(3), 573-589.

Bolat, H., Subaşi, S., Çullu, M., \& Akkaya, U. (2010). Beton Yolları Bekleyen Tehlikeler. Yapı Teknolojileri Elektronik Dergisi, 6(1), 30-37.

Chan, Y.-W., \& Chu, S.-H. (2004). Effect of silica fume on steel fiber bond characteristics in reactive powder concrete. Cement and concrete research, 34(7), 1167-1172.

Haddad, R. H., \& Smadi, M. M. (2004). Role of fibers in controlling unrestrained expansion and arresting cracking in Portland cement concrete undergoing alkali-silica reaction. Cement and concrete research, 34(1), 103-108.

Hınıslığlu, S., \& Bayrak, O. Ü. (2004). Optimization of early flexural strength of pavement concrete with silica fume and fly ash by the Taguchi method. Civil Engineering and Environmental Systems, 21(2), 79-90.

Hınıslıŏlu, S., \& Bayrak, O. Ü. (2005). A robust approach for evaluating modulus of elasticity of pavement concrete.

Institute, A. C. (1986). State-of-the art report on fiber reinforced concrete: reported by ACI Committee 544. ACI 544.1 R-82.

Joshaghani, A., Ramezanianpour, A. A., Ataei, O., \& Golroo, A. (2015). Optimizing pervious concrete pavement mixture design by using the Taguchi method. Construction and Building Materials, 101, 317-325.

Lee, J.-H. (2017). Influence of concrete strength combined with fiber content in the residual flexural strengths of fiber reinforced concrete. Composite Structures, 168, 216-225.

Lee, J.-H., Cho, B., \& Choi, E. (2017). Flexural capacity of fiber reinforced concrete with a consideration of concrete strength and fiber content. Construction and Building Materials, 138, 222-231.

Monteiro, P., \& Mehta, P. (1993). Concrete: Structure, properties, and materials. Prentice-Hall, Englewood Cliffs.

Müdürlüğü, K. G. (2016). Beton Yol Kaplamaları Teknik Şartnamesi. In. Ankara: Karayolları Genel Müdürlüŭü.

Neville, A. M. (1995). Properties of concrete (Vol. 4): Longman London.

Park, S.-B., \& Lee, B.-C. (2004). Studies on expansion properties in mortar containing waste glass and fibers. Cement and concrete research, 34(7), 1145-1152.

Peace, G. S., \& Peace, G. S. (1993). Taguchi methods: a hands-on approach: Addison-Wesley Reading, MA.

Richard, P., \& Cheyrezy, M. (1995). Composition of reactive powder concretes. Cement and concrete research, 25(7), 1501-1511.

Roy, R. K. (1990). A primer on the Taguchi method, competitive manufacturing series. New York, 7-80.

Song, P., Hwang, S., \& Sheu, B. (2005). Strength properties of nylon-and polypropylene-fiber-reinforced concretes. Cement and concrete research, 35(8), 1546-1550.

Taguchi, G. Tables of orthogonal arrays and linear graphs, Maruzen, Tokyo, 1962.

Toledo Filho, R., \& Sanjuan, M. (1999). Effect of low modulus sisal and polypropylene fibre on the free and restrained shrinkage of mortars at early age. Cement and concrete research, 29(10), 1597-1604.

Tunçel, M. U. (2018). Polipropilen Lif ve Kevlar Katkılı Yol Betonlarının Taguchı Yöntemiyle Optimizasyonu. (Yüksek Lisans Yüksek Lisans). Atatürk Üniversitesi, 